\title{
Participatory Sustainability Approach to Value Capture-Based Urban Rail Financing in India Through Deliberated Stakeholder Engagement
}

\author{
Satya Sai Kumar Jillella *, Annie Matan, Peter Newman
}

Curtin University Sustainability Policy (CUSP) Institute, Curtin University, Perth, WA 6845

E-Mails: s.jillella@postgrad.curtin.edu.au; anne.matan@curtin.edu.au; p.newman@curtin.edu.au

* Author to whom correspondence should be addressed; E-Mail: s.jillella@postgrad.curtin.edu.au; Tel.: +61-449-852-386; Fax: +61-892-669-031.

Received: 3 September 2014 / Accepted: 27 October 2014 / Published: 1 November 2014

\begin{abstract}
Increasingly cities around the world are seeking innovative financial mechanisms to build urban rail transit projects. Land value capture (VC) is a financing mechanism to fund urban rail transit. Often VC mechanisms are viewed only as a financing tool applied in relation to increased land values from the administration and legislation perspectives, without actively involving the community in the process. The lack of such participatory approaches has resulted in the under collection of the true value established. The transit beneficiary community and city tax payers are especially important stakeholders in this process as their willingness to participate is really critical to the overall VC success and transport outcome. This paper introduces a participatory sustainability approach identifying various stakeholder engagement interventions, and a set of appropriate deliberative democracy techniques across the VC life cycle. A four-step "Participatory Strategic Value Capture (PSVC)" framework is proposed offering step by step guidance toward facilitating a meaningful stakeholder dialogue, deliberation and collaboration around the stated engagement interests. The PSVC framework, applied to the proposed Bangalore suburban rail project in India, has demonstrated the importance of stakeholder engagement in order to enable sustainable development community goals and review VC strategies from a winwin perspective.
\end{abstract}

Keywords: Value Capture; Deliberative Democracy; Participatory Sustainability; Urban Land Values; Rail Transit Funding; Stakeholder Engagement 


\section{Introduction}

Globally, many cities are building rail transit infrastructure as a multi-functional solution to a range of urbanism challenges [1-3]. However many cities are struggling to find funds for these projects. Indian cities are no exception. Poor urban mobility can negatively impact the fast emerging developing economies like India, where cities primarily form the epicenter for such growth. Recently, cities in North America, Europe, Canada, Australia, New Zealand, and a few cities in Asia and Africa have opted for a monetization of increased urban land value through induced land value capture (VC) mechanisms as an alternate funding to build rail transit systems [3,8-10]. However, the VC concept is still perceived as a work-in-progress with varied success. As evident from these global experiences, there exists a notional misconception of VC mechanism as only a financing tool [15-17]. The majority of these practices looked at the VC process only from the fiscal policy, administration and legislation perspectives. Many of these practices lack clarity on the redistribution of the 'captured' gains beyond recovering the transit investment. Mostly they have overlooked the needed support investments for infrastructure integration and the sustainable community living aspects [17]. This paper will suggest how VC has the potential to move beyond being simply another tax tool to offer a powerful vision to enable sustainable community development goals to be incorporated [15].

Whether as a resident with transportation concerns or as a user of transit, streets or public spaces, a citizen's opinion is vital in help defining the VC process from planning to implementation [12]. Both the transit beneficiary community and the city tax payer community are potential key stakeholders in defining the VC process. Current VC practices so far have limited the community participation either to information sharing or to consultation only approaches. Moreover, the lack of participatory approaches in the VC process has led to an under-assessment and/or under-collection of the true value established and also the inability to fully explore the true potential of actual value created [17]. The success of VC thus depends on community engagement and their willingness to participate in the process.

There is limited research with regards to the community engagement aspects of the VC process, especially in a rail transit financing context. This current research fills this gap by introducing a comprehensive four-step "Participatory Strategic Value Capture” (PSVC) framework. This framework offers step-by-step guidance to interventions along with providing various approaches of undertaking stakeholder participation in order to define the VC process. The PSVC framework proposes a deliberated stakeholder engagement method using various Deliberative Democracy (DD) techniques that are relevant in a VC context. These techniques help facilitate meaningful deliberation which enables the co-creation of an inclusive and context specific VC strategy. This paper describes the application of the PSVC framework in the context of defining VC based financing for the proposed Bangalore suburban rail project using DD techniques. This paper first introduces a participatory sustainability approach within a VC context, proposes the PSVC framework and then describes its application in Bangalore to examine the benefits of utilizing participatory approaches in defining a VC process. It then assesses whether this PSVC framework has the potential to assist other cities 
worldwide looking to undertake a VC process to deliver public transport involving stakeholder engagement.

\section{Background to Participatory Sustainability Approach in a VC context}

Homes (2011) [20] (p.13) states that "engagement is not a single process or set of activities. It is an ongoing process or conversation that builds trust and relationship”. OECD (2003) [26] (p.30) classify stakeholder engagement into three forms of engagement: information sharing, consultation and participation. The first level, 'information sharing', is basically a one-way communication approach where information is passed from the decision makers to the stakeholders. The second level, 'consultation', is where stakeholders are able to contribute in parts of the decision making process but are not able (or empowered) to ensure that their aspirations are taken into account. Prior stakeholder participation in the VC process has been predominantly only in the first two stakeholder engagement approaches focusing mainly on 'information sharing' or 'consultation'. However, to be truly effective, the VC process needs to undertake a 'participation' approach to stakeholder engagement. The third level, 'participation', enables stakeholders to be actively involved in the decision making process [14, 26-27]. To this end, a participatory route utilizing DD methods is regarded as the most effective process that will enable positive outcomes. This is precisely the principle behind the participatory sustainability approach in VC context examined in this paper.

Stakeholder engagement is not a simple task, particularly when it comes to implementation, and especially as many stakeholders are disengaged and when certain groups within the population are marginalized [23]. A participatory approach therefore, demands a major paradigm shift by government agencies and community. Furthermore, a participatory approach might require stakeholders to acquire specialized skills in order to undertake successful collaboration. For example, Holmes (2011) [20] (p.1) highlighted that government or public agencies may be required to develop new roles as enablers, negotiators and collaborators, and at the same time, the community may be required to demonstrate a willingness to be actively engaged in the process (and dedicate time to the process) along with being sufficiently well informed to enable their participation and deliberation to be effective.

The expected benefits from stakeholder engagement utilizing a participatory sustainability approach within a VC context includes generating good will, removing uncertainty, and enabling community expectations to be at the forefront of decisions amongst other benefits. Furthermore it provides an opportunity to receive stakeholder support in the initial stages of the process and participation from the community helps to enable democratically agreed mutually beneficial VC ratios from the value created. If this agreement happens, it can help to enable the value captured to be re-distributed proportionately to related community support systems along with the transit investment that was necessary to enable the transit to be built. The PSVC framework to enable this participatory sustainability approach in VC context to be undertaken is described in the next section of this paper.

\section{Participatory Strategic Value Capture (PSVC) Framework}


The PSVC framework offers a platform from which to undertake a stakeholder engagement process in VC based rail transit financing projects. This framework requires the participation of all stakeholder groups at various stages of the VC process life cycle. This means involving stakeholders in all stages of the process, from the initial defining of the VC process to be used to the operationalization of the project on a continuous basis. The proposed PSVC framework is comprised of a sequential four-step stakeholder engagement model:

Step 1: Identify and classify the VC stakeholders groups.

Step 2: Define stakeholder engagement interventions and objectives across the VC life cycle.

Step 3: Identify appropriate DD techniques to be used across the VC life cycle.

Step 4: Periodic review of the effectiveness of stakeholder engagement across the VC life cycle.

Step four happens during the VC process life cycle and is ongoing.

Each of these steps will be described in detail in this section.

\subsection{Step 1: Identify and classify the VC stakeholder groups}

Step one involves identifying and classifying the necessary project stakeholders. Project stakeholders need to be identified at the outset of the project. The next step is to classify the identified stakeholders into specific groups based on their interests/relationship in the project. In a VC based transit financing project context, we can broadly classify the stakeholders into three major groups: investors, beneficiaries and community $[11-13,15,17]$. The three major stakeholder groups for an urban rail project along with the stakeholders that could be included in these groups and their aspirations are illustrated in Figure 1.

Figure 1: VC based urban rail financing project stakeholders and their aspirations

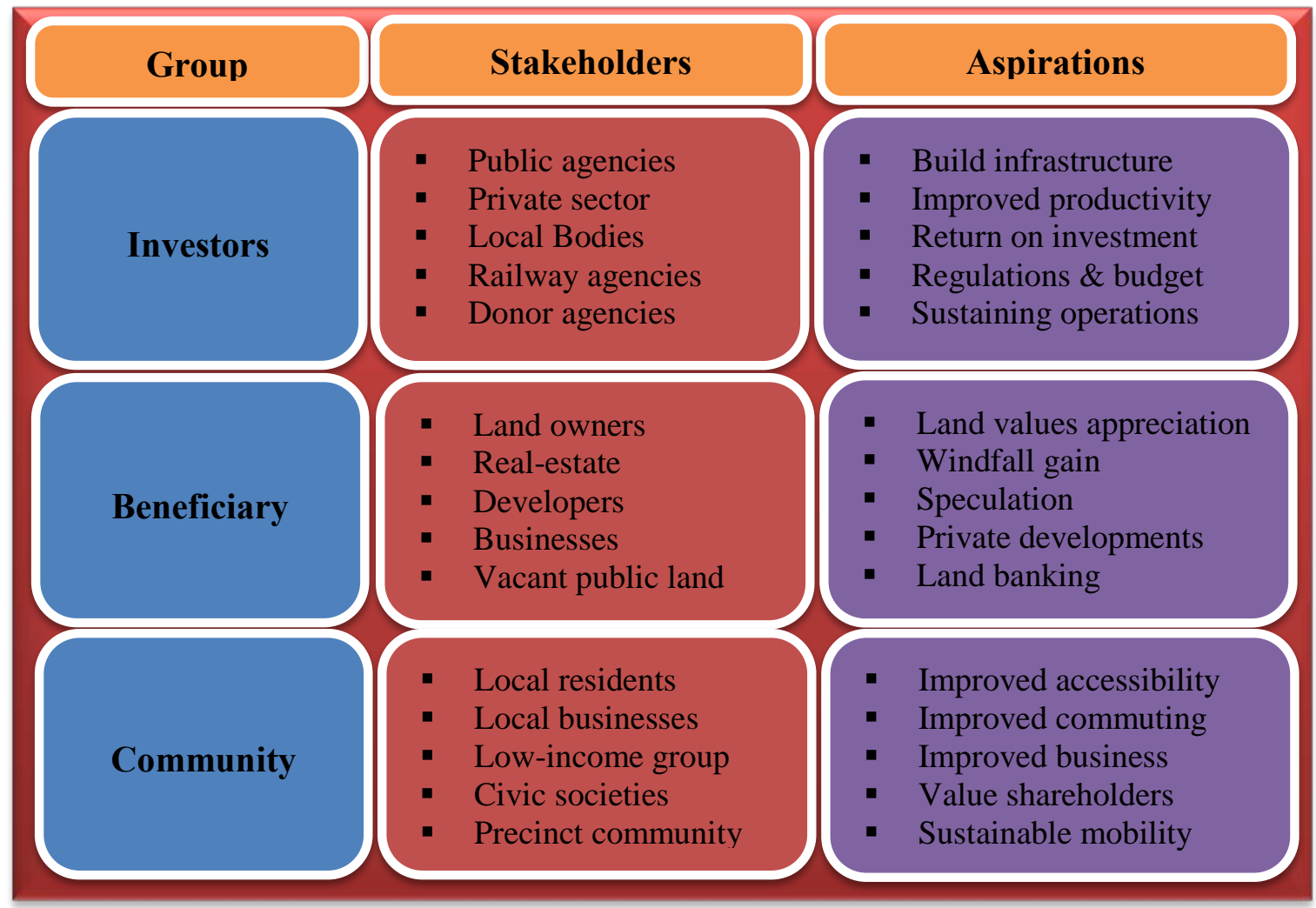


The first stakeholder group is the 'Investor' group. These are the stakeholders who provide the capital or investment in the project. They, along with providing a public good, also require a return on investment. The 'Beneficiary' group are those who benefit by the delivery of the project, generally through their proximity to the project, and with urban rail projects, from the increased accessibility, the increased property values, increased rents, agglomeration of new economies, and/or land use changes, etc. that happened due to the implementation of the rail project. The third group, the 'Community' group, include the local community members withe direct access to the project, particularly the low income community groups within the vicinity, and the city tax payer community at large $[15,17]$. Understanding the aspirations and cross-sectorial objectives of these groups provides a solid platform to be able to define the appropriate VC process to be undertaken.

\subsection{Step 2: Define stakeholder engagement interventions and objectives across the VC life cycle}

The second step involves defining the stakeholder engagement interventions and objectives across the VC life cycle. Figure 2 illustrates the VC life cycle classifying the entire VC process in six stages namely: initiation, planning and formulation, analysis and design, strategizing, execution and operationalization. The sustainable participatory approach recommends engaging stakeholders across all six stages of VC process life cycle. These stages are predominately similar in any VC based project however the key processes followed within each stage may vary slightly. The key processes of VC across each stage for any urban rail transit project are listed in Figure 2 along with the proposed engagement type, or set of engagement objectives, to facilitate these key VC processes are identified, across all the above six stages.

This can be further explained. For example: the first stage is 'initiation' which is the conceptualization phase where the possible transit network, alignment options, land use, legislation and regulation perspectives are considered. Engagement at this stage could include information sharing, communication of project goals, and the elicitation of the community views, the validation of the problem and determining the anticipated value addition through consultations. Similarly the second to fourth stages, 'planning', 'design' and 'strategize', include the process of defining and structuring the VC for the transit project. Indeed the actual process of VC planning, design and strategizing kick off during these phases. Stakeholder engagement during these phases would involve participation, deliberation, and co-creation from all groups as identified above and involves deliberating and agreeing on the various VC mechanisms to be utilized. The last two stages of VC life cycle, 'execute' and 'operate', drives the VC implementation and VC operationalization. During these last two VC phases, the set engagement interests are primarily collaboration, engagement, and empowerment through active participation in project steering groups and governance in order to ensure the set project objectives are achieved. 
Figure 2: Stakeholder engagement interventions across the VC life cycle

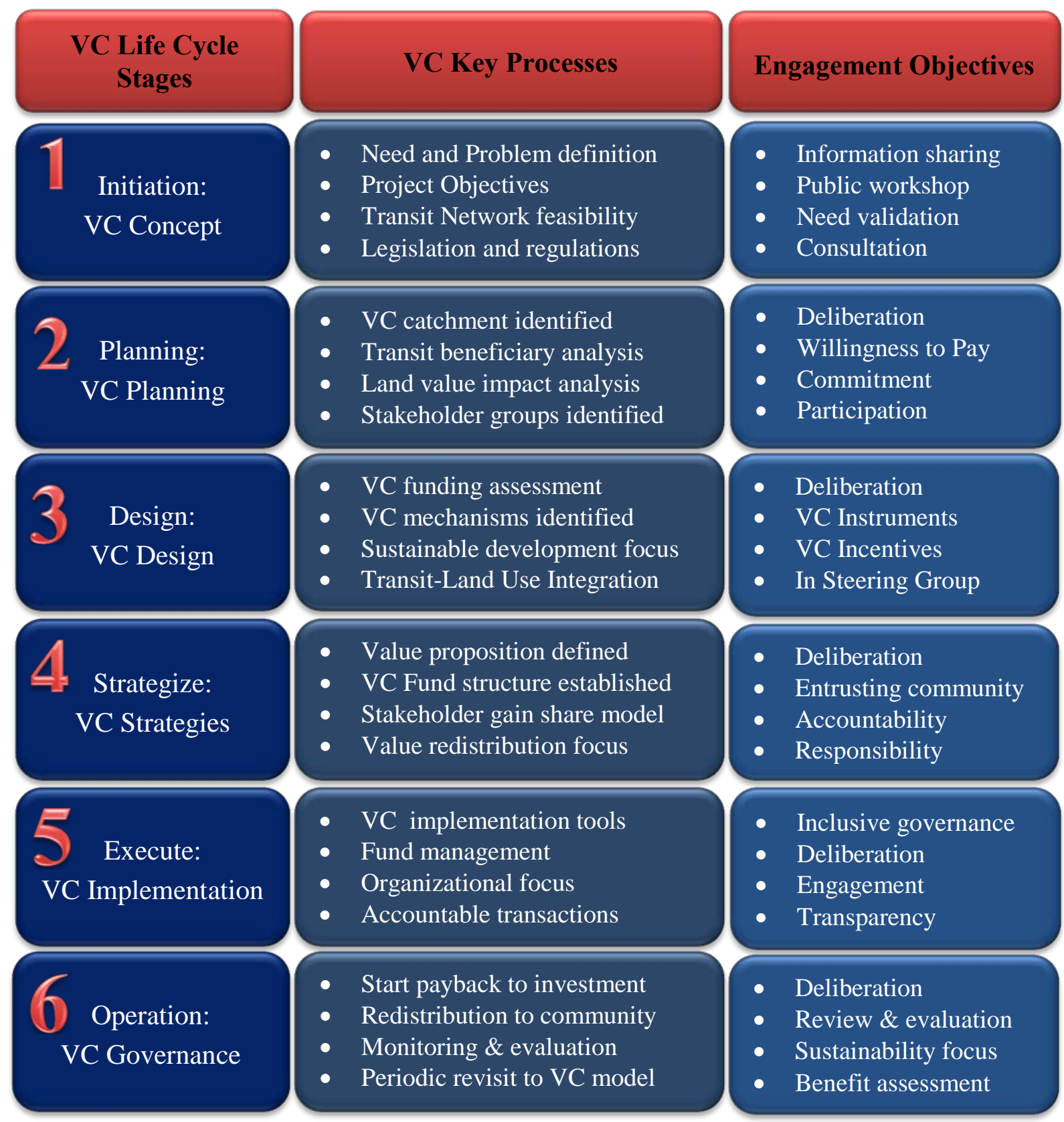

\subsection{Step 3: Identify appropriate DD Techniques and their application across the VC life cycle}

The third step facilitates the undertaking of stakeholder engagement by identifying appropriate DD engagement techniques that could be used across a VC life cycle. Primarily, this step focuses on establishing which engagement techniques might work best in each stage of the VC life cycle. DD techniques are helpful in enabling and facilitating a participatory sustainability approach in VC decision-making. Carolyn and Lars (2006) [23] (p.20) state that DD advances richer forms of public participation that engage citizens in a structured dialogue around focused policy issues, and yields benefits to participants and sponsors that extend beyond the collection of useful information. Carolyn and Lars (2006) [23] (p. 24-25, 31-32) recommended eight DD techniques to integrate public deliberation into agency decisions, namely; 'ChoiceWork Dialogue, Citizens Jury, Consensus 
Conference, Deliberative Polling, Issue Forums, Study Circles, $21^{\text {st }}$ Century Town Meeting, Citizen Assemblies'. These approaches seek to find 'broad support' from all key stakeholders for a policy direction. Similarly, Hartz-Karp (2013) [19] (p.45-90) suggests seven DD techniques that are suitable for a participatory sustainability approach to enable interactions, dialogue and ideally deliberation between all stakeholders. These, from the Hartz-Karp's (2013) 'The Participatory Sustainability Learning Guide' [19] (p.111-119), are recommended as suited to facilitate the VC stakeholder engagement process in the context of an urban rail project, and include:

1. Consensus Forum: This is a popular deliberation process in aiding shared understanding and meeting consensus in a complex and difficult decision making situations where a variety of stakeholders namely, public, private, resident community, and civic societies involved in decision making. This technique is particularly useful when the participants are more in numbers and representing divergent views on more intricate issues, or most argumentative issues toward aiding consensus based decision making process.

2. Multi-Criteria Analysis (MCA): The MCA technique is a structured iteration based deliberation technique leveraging scientific data and technology to help decision making process. This technique is a means of simplifying complex decision making tasks which may involve many stakeholders, a diversity of possible outcomes, and many, and sometimes intangible, criteria by which to assess the outcomes. This tool would help to prioritize a set of options identified with appropriate weightages assigned and rank them based on the pre-set deliberation objective.

3. World Café: This technique offers a simple, effective and flexible format for hosting large group dialogue using participatory rounds of shared interactions especially in joint visioning, planning and designing context to motivate networked exchanges in smaller group rounds. In this approach, participation is only by invite based on the purpose of the meeting. World cafés can be used across a specific issue or multiple issues where people engage in progressive rounds of conversations ascertaining questions related to a particular issue in each cluster.

4. 21st Century Town Meeting/Dialogue: This is an advanced technology enabled public forum that brings together a large number of people, organizes them into facilitated small discussion groups, and uses the latest software technology to analyze and provide instant feedback. Participants are linked through on-line networked computers and engage in informed deliberation in smaller groups through real-time feedback and deliberation to find common themes and priorities on most contentious issues. This primarily to seek substantive feedback on key issues, finding common ground and prioritize what is most important toward influencing decision making.

5. Open Space Technology: The Open Space Technology meeting is to create time and space for people to engage deeply and creatively around issues of concern to them. Later an open circle meeting is reconvened where all participants can give their comments as part of facilitated process. This followed with a final plenary session where participants can give comments and finally it provides the outcome with common understanding on defined goals, actions, milestones and responsibilities with a way forward. 
6. Local Area Forum: This technique is popular to bring together government, industry and community to determine optimal use of scanty resources through coordinated actions and joint collaboration. It is more representative of the local community and can get greater local ownership of issues. In this method, local community is more involved and empowered to make informed decisions on what community requires.

7. Strategic Questioning: This is a powerful problem solving technique to engage groups in innovative thinking, to develop strategy, to facilitate change, and to get acceptance to new ideas. Strategic questioning as a tool help to find creative ways in times of uncertainty, conflict and confusion and in case of current thinking appears to be constrained.

DD techniques cross referenced with VC life cycle and engagement objectives as shown in Figure 3.

Figure 3: Stakeholder engagement and DD techniques across a VC life cycle

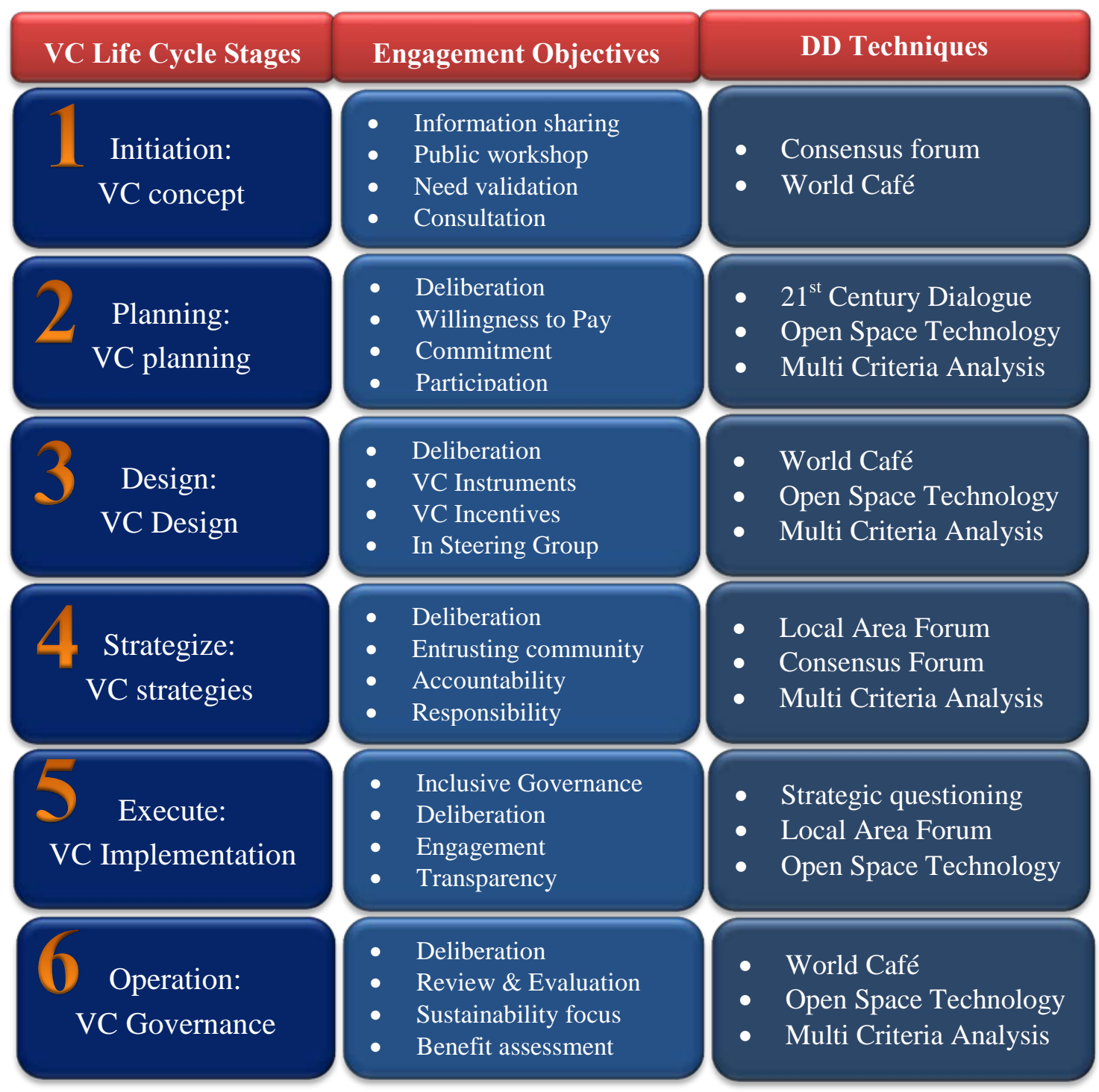

3.4 Step 4: Periodic review of the effectiveness of stakeholder engagement across the VC life cycle 
Step four involves reviewing the stakeholder engagement model undertaken and occurs after the process has started and is ongoing over the projects life cycle. A periodic review of the stakeholder engagement undertaken along with the VC progress needs to be conducted at least by the end of a respective stage of the VC life cycle. This helps in understanding the performance of the various stakeholder groups against the set objectives and targets. From time to time it is advisable to have a check point to measure the effectiveness of the engagement performance and also evaluate any risk groups or dependent activities. This is, however, project specific. Therefore at the beginning of the VC process itself, check points or stages to measure the performance need to be identified.

The next section of this paper describes how these PSVC framework steps could be applied in practice utilizing a case study of the proposed Bangalore suburban rail project.

\section{PSVC framework applied to the proposed Bangalore suburban rail project}

Bangalore city is urbanizing at an unprecedented scale and has a current population of over 8.5 million. The urbanization process has been defined by increasing urban sprawl and the development of a complex transport pattern. This urbanization process has presented a formidable commuting challenge today. The Comprehensive Traffic and Transportation Plan for Bangalore recommended the implementation of a suburban rail system to link Bangalore to surrounding cities within a radius of 50$70 \mathrm{~km}$ in order to help reduce dependence on road-based transportation [25]. Considering the potential benefits of suburban rail services, the State Government of Karnataka has given its in-principle approval for the project and preparation of a Detailed Project Report (DPR) for implementation has commenced [21]. Currently, the proposed suburban rail plan is to use the existing inter-state rail network of about $370 \mathrm{kms}$ to connect towns, suburbs and the inner city through introducing capacity and improving the frequency of operations.

Along with the DPR preparations, the Government of Karnataka is also keen to explore alternative innovative financing options to build the suburban rail. To this end, the Directorate of Urban Land Transport (DULT) from the Government of Karnataka State, India signed a memorandum of understanding with Curtin University Sustainability Policy (CUSP) Institute, Australia, and CiSTUP, Indian Institute of Science, to help facilitate a VC based funding strategy. According to the VC life cycle described above, the current progress of this suburban rail project can be defined as between the 'Initiation and 'Planning' stages. Though conceptually the project initiation and feasibility study was completed in 2013, the participatory route through stakeholder engagement has not been initiated so far.

Therefore, as part of this project, under the auspices of AusAID sponsorship, a two-day stakeholder deliberation workshop on "Bangalore Suburban Rail Project: potentials for innovative financing and planning strategies” was held on 9-10 October, 2013, in Bangalore, India. The objective of this workshop was to identify ways to innovatively finance the suburban rail project, and at the same time, achieve more equitable outcomes for all involved. The workshop used a participatory sustainability approach to which the PSVC framework is applied in order to demonstrate its use in practice, particularly the applicability of undertaking stakeholder engagement using appropriate DD techniques 
in a transport project context. The core question for the deliberation around using VC in the Bangalore Suburban Rail project was identified to be 'can we improve understanding and skills around transit oriented design and VC based suburban rail financing through stakeholder engagement using deliberative democracy techniques in Bangalore?' This project has enabled the testing of the application of the PSVC framework. The steps undertaken during this process are described in this section following the four steps described above, along with detailing the process so far, the outcomes and the way forward of this innovative project.

\subsection{Step 1: Identify and classify the VC stakeholder groups}

Following the PSVC framework classification, as the first step identified the stakeholders to be involved in this project. They were broadly identified from state government agencies, railway organizations, representing the 'investor' group; the local station resident and business groups, and community groups from suburban towns representing the potential 'beneficiary' groups and lastly, the community group stakeholders identified with representation from citizen forums, NGOs, experts and resident associations. The first day of the workshop deliberation involved about 80 high-level participants from a wide range of organizations and community members. The second day involved a smaller group of 26 key stakeholders to summarize and agree on the next steps. These Day 2 participants were selected in such a way that to ensure at least one or two representatives from the all identified stakeholder groups participated in the 'way forward' discussion. Primarily Day 1 with larger participation was planned for deliberation and Day 2 was planned to summarize the deliberation into action and agree on way forward.

\subsection{Step 2: Define stakeholder engagement interventions and objectives across VC life cycle}

Following the PSVC framework, this current project status is defined as post initiation and currently in planning stages of VC life cycle. This provided an opportunity to orchestrate the stakeholder engagement workshop during the second stage 'planning' of Bangalore suburban rail project. This workshop primarily focused on bringing together key stakeholders of the proposed Bangalore suburban rail to deliberate on innovative financing options using VC mechanisms and to determine a way forward that maximizes suburban rail attractiveness, sustainability, viability and accessibility. The stakeholder engagement objectives defined were to encourage deliberation on the identified core questions and understand stakeholder willingness to participate in the VC based financing process.

Keeping in mind that no prior stakeholder consultations had taken place during the project initiation stage except for a consultant study on project feasibility, it was decided to include a knowledge sharing session during the workshop on Day 1. This provided an opportunity to enable all stakeholders to understand land based VC financing mechanisms and hear from experts sharing global best practices. This was followed by a core group deliberation which included validating the VC concept with respect to its applicability to the proposed Bangalore suburban rail project. The key sub-questions discussed during the focused deliberations were: 'how can we make VC work in Bangalore?' and 'which one among them will be the most important to make VC work in Bangalore?' The deliberations concluded with a discussion about the constraints and opportunities to VC process in the Bangalore context. 
In future if the process was to follow the PSVC framework, a number of deliberation workshops would need to be organized as per the suggested stakeholder interventions across the VC life cycle stages as presented in Figure 2. These could include stakeholder participation across remaining stages of life cycle: the 'VC design', i.e., to identify the appropriate VC instruments to value assessment, stakeholder willingness to participate as appropriate in the project context. A project steering group with representation from stakeholder community could help in creating the 'roadmap' to strategizing the VC process. This would enable stakeholder involvement to move from participation to engagement. The following fourth stage, 'VC strategies' would set an agenda for the stakeholder community to jointly structure the VC fund and its redistribution strategies as identified upfront. Then in fifth stage, 'VC Implementation', and the last stage, 'VC Operationalization', enabling stakeholders to be part of VC governance would help review the project progress and evaluation of the VC process as measured by the stated engagement interests and commitments.

\subsection{Step 3: Identify appropriate DD Techniques and their application across VC life cycle}

This stage is about identifying the appropriate stakeholder engagement techniques as recommended by PSVC framework appropriate for the 'planning stage' of VC life cycle. The high level DD techniques identified for the Bangalore workshop deliberations were: $21^{\text {st }}$ Century Town Meeting/Dialogue, Multi Criteria Analysis and Open Space Technology [19] (p.85-88, 114).

On Day 1 two main DD techniques deployed were: 21st Century Town Meeting/Dialogue and Multi Criteria Analysis (MCA). On Day 2 the DD technique used was Open Space Technology technique. Day 1 involved small, facilitated groups, using networked computers linked to an innovative online software platform. This platform is designed to facilitate the finding of a common ground and common priorities. For key sub-questions, the responses received were classified in realtime into major themes, with the aid of on-line software, and then themes were reviewed and prioritized by participants with an appropriate score assigned to each using weightages. These themes

Figure 4: Participants showing the receipt of workshop report on real-time at the end of day 1 event

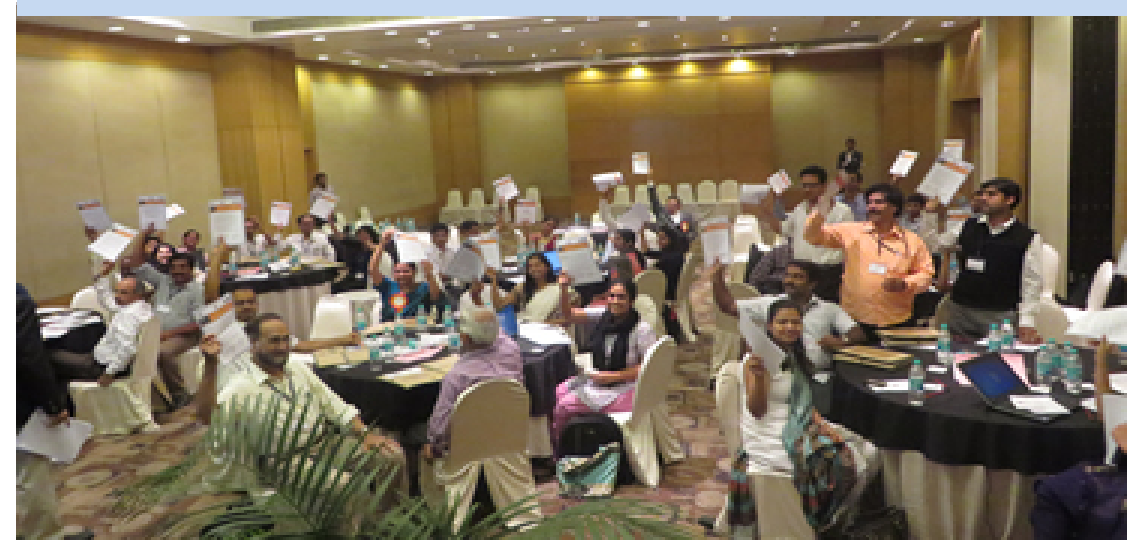
were ranked using the MCA technique. The participants also deliberated on constraints and opportunities around adopting VC in the context of the proposed Bangalore suburban rail project.

At the end of the Day 1 deliberations, a 'Workshop Outcome Report' detailing the key points from the day, including the expert presentations and the complete copy of workshop deliberations, key themes and prioritization scores was compiled and distributed to each participant. Participants were very excited to receive their report as shown in Figure 4. This presentation of the report was really important to maintain interest and enthusiasm with participants as it enabled 
participants to have key outcomes immediately, rather than waiting for a report to be produced a few weeks later as typical happens in traditional workshops [21]. The workshop on Day 2 used the Open Space Technology technique. On Day 2 about 26 key participants representing all stakeholder groups deliberated on the key outcomes from the previous day and then identified actions, task-owners, and milestones to moving forward.

\subsection{Step 4: Periodic review of the effectiveness of stakeholder engagement across the VC life cycle}

At the end of the event, the workshop results and processes were analyzed and the engagement model used was found to be very positive. Active deliberations were reflected from the results. All stakeholder groups unanimously agreed that land based VC financing was appropriate for the project and also suggested barriers and opportunities in the current system along with solutions for the alternatives proposed. Overall using the DD process uniquely transformed the role the public normally plays in traditional community consultation from combative and divisive to cooperative and cointelligent.

\subsection{Discussion}

The deliberation process around the potential of VC in Bangalore enabled real discussions across a variety of stakeholders and enabled potential oppositions or tensions to be considered and a variety of viewpoints to be expressed, debated and then a common understanding to be developed. For example stakeholders deliberated and discussed in smaller groups potential 'constraints and opportunities' to utilizing the VC process in the Bangalore suburban rail project. The group responses were classified in real-time with the aid of on-line software into major themes coming from the entire group. These themes were then prioritized. This technique facilitates iteration, enabling the group to continue discussing until a clear idea or action is identified. Indeed using the MCA technique with weightages prioritized the themes with their true order of importance in defining the VC process. From the example above, 'constraints and opportunities', the major constraint to utilizing VC in the Bangalore suburban rail project was collectively decided to be that "There is a lack of collaboration, coordination and capacity between and within agencies, with many conflicting interests. Better coordination is essential" and for opportunities "VC schemes are popular and offer opportunities for involvement with various stakeholders (private sector, developers, land owners and citizens)” [21]. From this the next steps can be determined and potential opposition can be aired and deliberated on so that a common understanding is developed and formalized through the workshop outcomes report. In this example this was undertaken very quickly, in 2 days, using the framework driven approach described above and overall stakeholder acceptance on VC process and the feasibility to the project was agreed. If the participatory sustainability approach had not been undertaken, then developing this common understanding may have taken a much longer time using more common stakeholder engagement processes, or not happened at all.

Moreover, the PSVC framework driven stakeholder engagement approach not only provided a platform for facilitating the development of a common ground but provided a source for crosspollination of new knowledge and new ideas to VC value assessment. For example, when the 
beneficiary group deliberated in smaller groups they deliberated on what the possible equity implications were and also the possible negativities they would face during the project construction phase. In reality, this group due to their proximity to project site do experience much greater pain, interruption to their businesses, traffic chaos, and other pollution related negativities during the project construction period. So the discussion around how this negative externality could be compensated from the increased land value gained later in the process and how this could be designed into the appropriate VC mechanism and also how this could be used to determine the value assessment criteria in VC design at later stage was had. These ideas and discussions may never have occurred without this deliberation. Secondly, the group deliberated on the commuter demand from the affordability criteria than proximity based traditional capacity estimates, which may often led to exaggerated demand. This is an important input for suburban rail capacity planning as the beneficiary community mainly provides the catchment capacity and also source for fare box revenues at a later stage. Lastly, participants identified support infrastructure like bicycle paths, foot paths, and auto-rickshaws parking, vehicle parking, smart fare systems, etc., as essential investments and critical to making the station accessible and suburban rail an attractive commuter choice. This enhanced the VC financing scope not only to cover the cost of the rail infrastructure provision but also to include the cost of providing the support infrastructure around the stations as well. Often, these support infrastructure investments are ignored during VC redistribution by rail authorities as most of such support infrastructure need to be provided by other government agencies. This again re-emphasizes the significance of the PSVC driven framework with a coordinated and participatory approach in defining and implementing the VC process.

The above are a few examples that highlight the significant value of the deployment of the PSVC framework driven participatory sustainability approach to positively contribute in enhancing the planning and design of VC process. The received inputs from the stakeholders were very useful for this planning stage and would greatly help to the Bangalore suburban rail VC design stage. As part of the next steps, post DPR study completion, it was agreed to initiate the value assessment along the identified suburban rail corridors to identify potential VC mechanisms and strategies to generate revenues.

Overall, participants found several meaningful opportunities to engage in public deliberation, policy development and decision-making during the workshop. Though it was a successful deliberation within the given constraints of time, the stakeholder participation has not yet translated into engagement levels. As the project is still in a planning stage as a work-in-progress, further stakeholder engagement needs to be continued throughout the life cycle of the VC process. Another important immediate future step is to identify key stakeholders to be a project steering group. Thus the PSVC framework, applied to the proposed Bangalore suburban rail project in India, has demonstrated the importance of stakeholder engagement in order to enable sustainable development community goals and review VC strategies from a win-win perspective.

\section{Conclusions}


VC integrates the land use and transit system to enable an alternate revenue source which is traditionally ignored due to a flawed revenue focus [4]. However just doing VC as a pure revenue raiser instead of incorporating a participatory approach is likely to lead to inequitable results. A participatory approach is thus an essential element of all VC planning and implementation processes. Stakeholder participation enables concerned parties to understand each other's requirements and limitations and allows them to work together to reach solutions in consensus. To this end, the PSVC framework described in this paper provides a unique attempt to enable stakeholder participation in the VC process and also enable stakeholder participation to strengthen the outcomes of the VC process. The PSVC framework utilizes deliberative democracy stakeholder engagement techniques. These enable each person to meaningfully participate. The PSVC framework is described and tested in the Bangalore Suburban Rail case study. The framework has the potential to provide an important step forward in mobilizing stakeholder support to the innovative financing option of VC as well as potentially enabling the VC process to explore its true potential. The results suggest that the PSVC framework provides a powerful tool to visualize the value of the project from all stakeholders and also enables increased acceptance and understanding of the project. The PSVC framework also enables the minimization of risks through the early involvement of the stakeholder groups (investors, beneficiaries and the community). Furthermore, the PSVC framework has the potential to be applied to stakeholder engagement in any VC based transit financing project globally and could be extended to other forms of VC based urban infrastructure investment by modifying the objectives and the stakeholder groups to reflect the context of the project.

In conclusion, stakeholder driven VC approaches can shape and reshape any transit oriented development in compliance with sustainable development goals including community aspirations with well-defined value creation and value redistribution strategies upfront.

\section{Acknowledgments}

The authors gratefully acknowledge the support provided by the Directorate of Urban Land Transport (DULT) of State Government of Karnataka, India and CiSTUP, Indian Institute of Science in jointly organizing the Bangalore suburban rail workshop. The authors also would like to thank AusAid, PATREC and Curtin University for the research grant. The authors would like to extend sincere thanks to Prof. Janette Hartz-Karp of Curtin University, Australia for her excellent training inputs on participatory sustainability and deliberative democracy approaches and for her leadership to successfully conduct the Bangalore workshop in India.

\section{Conflicts of Interest}

The authors declare no conflict of interest.

\section{References and Notes}

1. Newman, P. and Kenworthy, J. Sustainability and Cities Overcoming Automobile Dependence, $1^{\text {st }}$ ed.; Island Press, Washington, DC 20009, USA, 1999; pp. 116-118. 
2. Newman, P., Glazebrook, G., and Kenworthy, J. The Rise and Rise of Global Rail: Why this is happening and what it means for large and small cities, Transport Reviews, 2013.

3. Cervero, R. and Duncan, M. Rail's Added Value, Urban Land, 2002, 61:2: 77-84.

4. Cervero, R., Linking Urban Transport and Land use in Developing Countries, The Journal of Transport and Land Use, 2013, Vol 6, No 1, 7-24.

5. Cervero, R. Rail Transit and Joint Development: Land Market Impacts in Washington, DC and Atlanta, Journal of the American Planning Association, 1994, 60:1, 83-94.

6. Suzuki,H., Luchi, K., and Cervero, R. Transforming cities with transit: Transit and L and-use Integration for Sustainable Urban Development, The World Bank, Washington, DC., USA, 2013.

7. National Urban Transport Policy (NUTP), India, 2006. Available online: http://urbanindia.nic.in/ policies/ TransportPolicy.pdf (accessed on 0509 2014).

8. Smith, J.J., and Gihring, T.A. Financing Transit Systems Through Value Capture: An Annotated Bibliography, American Journal of Economics and Sociology, 2006, 65 (3), 751-786.

9. Scheurer, J., Newman, P., Kenworthy, J. and Gallagher, T. Can Rail Pay? Light Rail Transit and Urban Redevelopment with Value Capture Funding and Joint Development Mechanisms, Institute for Science and Technology Policy, Murdoch University, Australia, 2000.

10. William Bhat H., Value Capture as a Policy Tool in Transportation Economics: An Exploration in Public Finance in the Tradition of Henry George, the American Journal of Economics and Sociology, 2001.

11. Smolka, M.O., Implementing Value Capture in Latin America: Policies and Tools for Urban Development, a Policy Focus Report, the Lincoln Institute of Land Policy, Cambridge, MA, USA, 2013.

12. Smolka, M.O., A New Look at Value Capture in Latin America, Land Lines, 2012, 24(3): 10-15.

13. Smolka, M.O., et al. Mobilizing Land Value Increments to Provide Serviced Land for the Poor, Land Lines, 1999, 11(4).

14. OECD, Focus on Citizens: Public Engagement for Better Policy and Services, 2009, Available online: http://www.oecd.org/ dataoecd/ 20/3/42658029.pdf (accessed on 0808 2014).

15. Wolf-Powers, L., "Community Benefits Agreements in a Value Capture Context" Value Capture and Land Policies. Ed. G.K. Ingram and Y. Hong. Cambridge, MA: Lincoln Institute of Land Policy, 2012, pp. 217-232.

16. Gross, J., CBAs: Definitions, values, and legal enforceability, Journal of Affordable Housing and Community Development Law, 2008, 17(1-2):36-58.

17. John Walker, Land Value Capture and Infrastructure Delivery through SLICs, T\&CP Tomorrow Series Paper 13, TCPA, UK, 2012.

18. $\mathrm{Mu}, \mathrm{R}$., and Jong, M.De., Establishing the conditions for effective transit-oriented development in China: the case of Dalian, Journal of Transport Geography, 2012, 24:234-249.

19. Hartz-Karp, J., Deliberative Democracy: Techniques that Create Opportunities for Joint Decisionmaking, Participatory Sustainability (302475) Unit Information and L earning Guide, Curtin University of Technology, Perth, Australia, 2013, SS 542, pp 45-119.

20. Holmes, B. 2011, Citizens' Engagement in Policymaking and the Design of Public Services, research paper no. 1, 2011-12, Australian Parliamentary Library, Canberra. 
21. Newman, P., and Matan, A., Report on Stemming Car Dependency and Improving Transport Options in Indian Cities, AusAID Public Sector Linkage Program Project (65080), Curtin University Sustainable Policy (CUSP) Institute, Australia, 2013.

22. McIntosh, J.; Newman, P.; Crane, T.; Mouritz, M. Alternative Funding Mechanisms for Public Transport in Perth: The Potential Role of Value Capture, Discussion Paper; Curtin University Sustainability Policy Institute: Perth, Australia, 2011.

23. Carolyn, J.L., and Lars, H.T., Public Deliberation: A Manager's Guide to Citizen Engagement, IBM Center for The Business of Government, 2006. Available online: http://www.businessofgovernment.org/sites/default/files/LukensmeyerReport.pdf (accessed on 20 09 2014).

24. Wilbur Smith Associates, Comprehensive Traffic and Transportation Study (CTTS) for Bangalore Metropolitan Region, DULT, Government of Karnataka, India, 2010

25. RITES, India., Comprehensive Traffic and Transportation Plan (CTTP) for Bangalore Metropolitan Region, DULT, Government of Karnataka, India, 2011

26. OECD, Promise and Problems of E-Democracy, 2003, Organization for Economic Cooperation and Development (OECD), Paris, Available online: http://www.oecd.org/governance/publicinnovation/35176328.pdf (accessed on 1009 2014).

27. OECD, Citizens as Partners: OECD Handbook on I nformation, Consultation and P ublic Participation in Policymaking, 2001, Organization for Economic Cooperation and Development (OECD), Paris, Available online: http://internationalbudget.org/wp-content/uploads/Citizens-asPartners-OECD-Handbook.pdf (accessed on 0809 2014).

(C) 2014 by the authors; licensee MDPI, Basel, Switzerland. This article is an open access article distributed under the terms and conditions of the Creative Commons Attribution license (http://creativecommons.org/licenses/by/3.0/). 